\title{
A REPERCUSSÃo DA CONSTITUCIONALIZAÇÃO SOBRE OS DIREITOS DA PERSONALIDADE: EM BUSCA DA DIGNIDADE DA PESSOA HUMANA
}

THE REPERCUSSION OF CONSTITUTIONALIZATION ON THE RIGHTS OF PERSONALITY: IN SEARCH OF THE DIGNITY OF THE HUMAN PERSON

\section{Danielle Spencer HOLANDA ${ }^{1}$}

ISSUE DOI: $10.21207 / 1983.4225 .934$

\section{RESUMO}

O presente artigo analisa a influência da constitucionalização sobre os direitos da personalidade. Discorre sobre o processo de constitucionalização do direito. Esclarece sobre sua (a)tipicidade. Ressalta

${ }^{1}$ Doutorado em Direito pela Universidade Federal de Pernambuco (UFPE), Recife/PE. Mestrado em Direito pela Universidade Federal de Pernambuco (2005). Pós Graduada em Direito do Trabalho e Processo do Trabalho pela Universidade Candido Mendes, em convênio com o Instituto a Vez do Mestre - IAVM e o DIEX (2007). Graduação em Direito pela Universidade Católica de Pernambuco (2001). Membro da Comissão do Direito de Família da OAB-PE (2017 a 2018). Coordenadora do Núcleo de Gestão do Consumidor pela Escola Superior de Advocacia Professor Ruy Antunes-OAB-PE (2016 a 2018). Coordenadora do Curso de Direito das Faculdades Integradas Barros Melo (2008.1 a 2009.2). Coordenadora das Atividades Monográficas do Curso de Direito das Faculdades Integradas Barros Melo (2011 a 2013). Atualmente é Professora da Faculdade Damas da Instrução Cristã, Faculdade Maurício de Nassau e Universidade Salgado de Oliveira. Possui experiência na área de direito, com ênfase em Direito Civil e Consumidor. Currículo Lattes: http://lattes.cnpq.br/6682944506108146. Contato: daniellespencer12@hotmail.com. 
a importância da aplicação dos princípios constitucionais sobre o tema. Demonstra a conexão entre seu conteúdo e os valores da dignidade da pessoa humana.

Palavras-chave: Direitos da personalidade. Constitucionalização. Dignidade da pessoa humana.

\section{ABSTRACT}

This paper analyzes the influence of constitutionalization on personality rights. Discusses the process of constitutionalization of law. Clarifies your (a) typicality. Emphasizes the importance of applying constitutional principles on the topic. It demonstrates the connection between its content and the values of human dignity.

Keywords: Personality rights. Constitutionalization. Dignity of human person.

\section{DA CONSTITUCIONALIZAÇÃO DO DIREITO CIVIL}

O processo de constitucionalização pode ser traduzido, segundo Pietro Perlingieri $(2008$, p. 177) pela análise da ordem social sob dois enfoques: o "ter" (aspecto patrimonial e mercantil da organização social, pertencente à estrutura econômica e produtiva) e o "ser" (aspecto existencial da pessoa).

O primeiro consagra um Estado, cuja função é manter a ordem, não se interessando em intervir nas situações pré-constituídas, mantém-se, portanto, a ordem dos direitos adquiridos. É o chamado Estado liberal, ou de polícia ou guardião noturno, o qual concede uma liberdade ao cidadão em relação ao Estado, cuja preocupação maior era oferecer garantias ao cidadão mediante a estrutura estatal. Já o segundo conduz a um Estado, cujo objetivo é resguardar a pessoa em toda a sua dimensão ontológica e, através dela, seu patrimônio e, para isso, fez-se necessário regular a ordem econômica e social. É o que se denomina de Estado social, o qual impõe limites à liberdade individual, tendo em vista caráter solidário que norteia o sistema. Em outras palavras, a constitucionalização representa, segundo Paulo Lôbo (2005, p.3), o processo de elevação ao plano constitucional dos princípios fundamentais do direito civil, superando-se antigos paradigmas como a separação dos espaços público e privado.

Outrossim, convém destacar que a passagem do Estado liberal ao social, a qual ensejou o processo de constitucionalização do direito, conforme entendimento de Gustavo Tepedino (2000, p. 327-342), pode ser divida em "eras". Dessa forma, inicialmente, pode-se dizer que o Código Civil assumia a figura de ordenador único das relações privadas e as leis extravagantes (legislação de emergência) eram adotadas de modo excepcional, casuística, de maneira que não abalasse o alicerce do direito 
civil, observando-se a Era da Codificação. Todavia, a partir da década de 30, houve uma sucessão de leis que disciplinavam matérias não reguladas pela codificação, não podendo mais aplicá-las de forma episódica, o que retirou a exclusividade do Código Civil às aludidas relações. Assim sendo, o Código Civil era aplicável ao direito comum e as leis extravagantes ao direito especial, paralelo àquele. Vislumbrava-se a chamada Era de Descodificação, na qual, segundo Ricardo Luis Lorenzetti (2003, p. 221), a tarefa do intérprete tornou-se decisiva, pois, aqui, o ordenamento codificado foi substituído pelo sistema de normas fundamentais. Posteriormente, tem-se a Constituição de 1988, inaugurando a denominada Era dos Estatutos, a qual proporcionou em seu texto constitucional uma "maior eficácia aos institutos codificados, revitalizando-os, mediante uma nova tábua axiológica" (TEPEDINO, 2000, p. 340), mediante a adoção de princípios constitucionais nas vicissitudes das situações jurídicas subjetivas, encontrando a dignidade da pessoa humana no ápice do ordenamento e assumindo a Constituição o papel central da unificação do ordenamento jurídico.

Um bom exemplo da interferência das normas constitucionais sobre os institutos do direito civil é a superação do debate sobre a tipicidade dos direitos da personalidade ou sua individuação (arts. 11 e segs. do CC/02), o que acarretaria a exclusão de qualquer outra manifestação existencial da pessoa e, particularmente, dos chamados direitos fundamentais; Para tanto, impõe-se a presença, na Constituição, de numerosas previsões de direitos civis e de liberdades civis, unidas à cláusula geral de tutela do livre desenvolvimento da pessoa humana (art. $1^{\circ}$, III, $\mathrm{CF} / 88$ ), o que permite analisar a pessoa em termos qualitativos $\mathrm{e}$ não quantitativos, de maneira a elevá-la ao centro do ordenamento, estendendo a sua tutela e relevância objetiva. Impõe-se observar a pessoa na sua ontologia e, por meio dela, o seu patrimônio.

Ao redefinir o fundamento e extensão dos institutos jurídicos codificados, destacando os seus perfis funcionais, estar-se-á revitalizandoos à luz de um juízo de valor. Isso faz com que o Direito Civil fique mais harmonizado com os princípios fundamentais e com as necessidades existenciais da pessoa.

\section{DOS DIREITOS DA PERSONALIDADE}


Atualmente, devido ao nível elevado do desenvolvimento científico e tecnológico, a proteção à dignidade da pessoa humana é analisada como uma necessidade imediata. Fazendo da seara dos direitos da personalidade seu habitat natural.

Importa ressaltar que esses direitos encontram-se inseridos no fenômeno da chamada repersonalização do direito civil, ao observar a pessoa como fundamento das relações civis, em detrimento do patrimônio, fruto do processo de constitucionalização do direito, como analisado no item anterior. Considera-se, pois, um desafio aos civilistas, consoante entendimento de Paulo Lobo (1999, p. 103), com o qual perfilho, ver a pessoa em toda a sua dimensão ontológica e, assim, seu patrimônio. Esse, também, é o posicionamento de Maurício D’Oliivo (1996, p. 185), pelo que se constata em seu artigo, eis que

[...] a personalidade faz parte do indivíduo, é a parte que lhe é
intrínseca, pois através dela, a pessoa poderá adquirir e defender os
demais bens. Como um bem do homem, a personalidade poderá ser
defendida contra quaisquer agressões. Através de normas do direito
positivo, a coletividade autoriza o homem a cuidar e defender os
seus demais bens.

Enaltecer o ser humano torna-se uma condição básica para se adequar o direito à realidade e aos fundamentos constitucionais.

Inicialmente, cumpre esclarecer o conceito, a natureza e extensão dos direitos da personalidade, estão intimamente ligados pela adoção da tese naturalista ou da cláusula geral do direito da personalidade ( $\operatorname{art} .1^{\circ}$, III, $\mathrm{CF} / 88$ ), ou mesmo, da sua atipicidade.

\section{$1.1 \quad$ (RE)DEFININDO-OS}

É imprescindível estabelecer o conceito de personalidade, uma vez que, por meio dele, alcança-se o âmbito dos direitos da personalidade. A personalidade é, segundo Pietro Perlingieri (1997, p. 155-156), um valor encontrado na base de uma série aberta de situações existenciais, exigindo, assim, sua incessante mutável tutela. Compõe-se de características que a distinguem como ser humano, ao mesmo tempo em que integra a sociedade e o gênero humano (MONTEIRO, 2003, p. 96).

Por sua vez, as situações subjetivas podem ser existenciais ou patrimoniais, merecendo proteção pelas funções sociais que exercem. 
Assim, o que define a situação subjetiva como existencial ou patrimonial é o interesse inserido no seu núcleo. Dessa maneira, "as situações referentes à propriedade, ao crédito etc, são tidas como relações patrimoniais, enquanto as situações referentes aos chamados direitos da personalidade são tidas como situações existenciais" (FACHIN, 1998, p. 33).

Daí, pode-se afirmar que os direitos da personalidade, segundo Carlos Aberto Bittar (1989, p. 1), são aqueles reconhecidos à pessoa humana considerada em si mesma e em sua projeção na sociedade; e consagrados pelo ordenamento jurídico para a defesa de valores inatos no homem, concretizando, assim, o princípio da dignidade da pessoa humana. Essa relevância jurídica só foi possível em virtude da constitucionalização dos direitos fundamentais, pois os direitos da personalidade são espécies do gênero direitos fundamentais. Consequentemente, o direito da personalidade é, conforme Pontes de Miranda (1971, p. 7), ubíquo, pois tanto se encontra amparado pelo direito público (ao se analisar como espécie dos direitos fundamentais) quanto pelo direito privado (ao observálo como relação de igualdade presente no direito civil). Portanto, não mais se vislumbra a velha dicotomia entre os espaços público e privado.

Os direitos da personalidade são todos os direitos necessários à realização da personalidade bem como à sua inserção nas relações jurídicas, constituindo prerrogativas ou faculdades que permitem a cada ser humano o desenvolvimento de suas aptidões e energias tanto físicas como espirituais, que integram o conteúdo essencial da personalidade (MIRANDA, 2000, p. 31-39).

Outrossim, segundo os positivistas, como De Cupis (2004, p. 2024), o ordenamento jurídico é árbitro na atribuição da personalidade e os direitos da personalidade configuram direitos subjetivos, constituindo o minimum necessário e imprescindível ao seu conteúdo. Todavia, os naturalistas, como Carlos Alberto Bittar (1989, p. 6-8), defendem que esses direitos se relacionam com atributos inerentes à condição de pessoa humana, portanto, direitos inatos, cabendo ao Estado reconhecê-los e sancioná-los em um ou outro plano do direito positivo (constitucionalmente ou ordinariamente), dotando-os de proteção própria contra o arbítrio do poder público ou contra as incursões dos particulares.

Reduzir o Direito a normas positivas importa em nomear o Estado como único definidor e identificador dos direitos, contrariando a noção recente de Estado e o velho brocardo jurídico, o qual preconiza existência anterior do homem à sociedade e esta ao direito. 
Verifica-se, portanto, que a concepção naturalista permite reconhecer a existência de direitos da personalidade não tipificados pelo ordenamento jurídico, os quais merecem ser amparados, pois decorrem do princípio geral da proteção da dignidade da pessoa humana (BELTRÃO, 2005, p. 24). É o posicionamento defendido por Luciana Fregadolli (1997, p. 197-199), o qual é adotado no presente texto, eis que

\begin{abstract}
Assim, a personalidade é parte do indivíduo, a parte que lhe é intrínseca, pois através dela a pessoa poderá adquirir e defender os demais bens. Todo homem tem a sua personalidade, independentemente do que o manda o Direito. [...] $\mathrm{O}$ direito objetivo autoriza a pessoa a defender sua personalidade, de forma que os direitos da personalidade são os direitos subjetivos da pessoa de defender o que lhe é próprio, ou seja, a identidade, a liberdade, a sociabilidade, a reputação, a honra, a autoria etc. São direitos comuns da existência, porque são simples permissões dadas pela norma jurídica, a cada pessoa, de defender um bem que a natureza lhe deu, de maneira primordial e direta.
\end{abstract}

É importante destacar, relativamente à natureza desses direitos, que sua determinação decorre da sua própria função em satisfazer as necessidades próprias das pessoas, identificando-se com os bens máximos, sem os quais os demais perdem todo o valor. Assim, percebe-se que a incerteza e ambiguidade do assunto é fruto da incidência dos valores jurídicos da pessoa no instituto da propriedade, reduzindo toda relação privada à categoria do ter e gerando uma incompatibilidade com o fenômeno da repersonalização. De fato, os direitos da personalidade evidenciam o ser e não o ter.

Doutrinariamente, discute-se a existência de um direito geral da personalidade, cujo conteúdo abrangeria todos os demais, tendo em vista a impossibilidade, ou mesmo, a dificuldade, de se prever legalmente todas as suas espécies, o que implicaria na recusa de tutela jurídica a situações atípicas.

A temática repousa na natureza aberta ou fechada da tipicidade dos direitos da personalidade. A doutrina tradicional reconhece os direitos da personalidade como típicos (tipicidade fechada), devido à concepção patrimonialista das relações civis, característica dos códigos oitocentistas. De fato, a preocupação com o ter foi refletida na estrutura do Código Civil de 1916, época em que o Estado, liberal, não interferia nas relações econômicas. Atualmente, esse posicionamento encontra-se obsoleto; não se coaduna, pois, com o advento do Estado social, marcado pela reverência ao ser e, consequente, intervenção econômica. $\mathrm{O}$ ser, pessoa, se realiza por 
meio de variadas manifestações humanas, as quais se modificam a depender dos fatores tempo e necessidade, e tantas quantas forem essas situações, devem elas merecer o devido amparo legal.

Aqui se combate à ideia de que os direitos da personalidade são típicos, ou seja, fora das hipóteses legais estabelecidas, ou pelo Código Civil, ou pelas leis especiais, ou pela Lei Maior, não existiriam outras espécies de direitos da personalidade. Não se deve falar em um número fechado de hipóteses tuteladas - realmente -, tutelado é o valor da pessoa sem limites, salvo aqueles colocados no seu interesse e naqueles de outras pessoas. A tutela da pessoa não se fracionaria em isolados suportes fáticos, em autônomas hipóteses não comunicáveis entre si, mas deve ser apresentada como problema unitário, dado o seu fundamento representado pela unidade do valor da pessoa. Assim, "além dos tipos de direitos da personalidade já positivados na Constituição e na legislação civil, os tipos socialmente reconhecidos são aferíveis a partir de sua compatibilidade com o princípio da dignidade da pessoa humana, fonte determinante de todos" (LÔBO, 2009, p. 144), o que possibilita a plena aplicabilidade dos direitos da personalidade.

Daí, afirmar que a personalidade é um valor e que está na base de uma série aberta de situações existenciais, não impedindo que o ordenamento preveja algumas expressões que julgue mais qualificantes (PERLINGIERI, 1997, p. 155-156), como tipos gerais.

Não resta dúvida que o nosso país adotou essa nova tendência, pelo que se constata no preâmbulo do texto constitucional ao preconizar, taxativamente, os valores supremos, assegurados pelo Estado social e que devem reger a nossa sociedade. Além disso, a Lei Maior traz como um dos fundamentos da República o respeito ao princípio da dignidade da pessoa humana, dentro do qual se configura os chamados direitos da personalidade, a isso se chamaria cláusula ou direito geral da personalidade. A dignidade da pessoa humana é, portanto, o centro de sua personalidade, e, por isso, merece a maior proteção.

Assim sendo, a personalidade humana mostra-se insuscetível de recondução a uma 'relação jurídica-tipo' ou a um 'novelo de direitos subjetivos típicos', sendo, ao contrário, valor jurídico a ser tutelado nas múltiplas e renovadas situações em que o homem possa se encontrar a cada dia. Daí resulta que o modelo do direito subjetivo tipificado será necessariamente insuficiente para atender às possíveis situações subjetivas em que a personalidade humana reclame tutela jurídica. Até porque, a 
realização plena da dignidade humana, explicitada no texto constitucional, não se conforma com a setorização da tutela jurídica ou com a tipificação de situações previamente estipuladas, nas quais pudesse incidir o ordenamento. Nessa mesma linha de raciocínio, esclarece Gustavo Tepedino (1999, p. 36) que "não se trataria de enunciar um único direito subjetivo ou classificar múltiplos direitos da personalidade, senão, mais tecnicamente, de salvaguardar a pessoa humana em qualquer momento da atividade econômica,".

Verifica-se, pois, que só é permitido restringir os direitos inerentes à pessoa quando se justifica na própria dignidade da pessoa humana.

Portanto, correto é o posicionamento abaixo sustentado de que

A tipificação dos direitos da personalidade deve ser entendida e operacionalizada em conjunto com a proteção de um direito geral da personalidade (um e outro se completam). Onde não houver previsão tipificada, o operador do direito leva em consideração a proteção genérica (FACHIN, 1998, p. 47).

Insta, pois, superar a tipicidade das situações subjetivas existenciais de outrora, peculiar do Estado liberal, permitindo, com isso, aflorar uma nova visão de pessoa, sua repersonalização, característica, pois, da denominada constitucionalização do direito civil, fenômeno singular do Estado social. Quem sabe, assim, poder-se-á garantir amplamente a pessoa humana!

Importa ressaltar, ainda, a relação entre a atipicidade e a cláusula geral de tutela da personalidade, amparada no princípio fundamental da dignidade da pessoa humana (art. $1^{\circ}, \mathrm{III}, \mathrm{CF} / 88$ ), que, ao lado da tipicidade social reconhecida, estabelece os limites mais amplos da consideração dos tipos. Dessa forma, são tipos de direitos da personalidade - àqueles previstos na Constituição e na legislação civil e os reconhecidos socialmente e conformes com a cláusula geral (LÔBO, 2001, p. 85).

A pessoa, à luz do sistema constitucional, requer proteção integrada, que supere a dicotomia direito público e direito privado e atenda à cláusula geral fixada pelo texto maior, de promoção da dignidade humana.

\subsection{REFLETINDO SOBRE SEU CONTEÚDO}


No tocante à sua extensão, nada mais do que reflexo da sua atipicidade, a posição dominante classifica esses direitos em duas categorias: integridade física e integridade moral, o que possibilita sua sistematização e evidencia diferentes direitos. No entanto, a evolução possibilitou, por meio da ação da jurisprudência e da doutrina, a inserção de novos direitos, os quais posteriormente deverão ser reconhecidos pelo direito positivo.

Observa-se, pois, a seguinte distribuição quanto ao tema: a) direitos físicos (corpo, órgãos, membros, imagem), b) direitos psíquicos (liberdade, intimidade, sigilo) e c) direitos morais (identidade, honra, manifestações do intelecto). Constata-se, então, a referência, de um lado, à pessoa em si (patrimônio físico e intelectual, originários, existentes por sua natureza, como ente humano, com o nascimento); e, de outro, sua projeção na coletividade (patrimônio moral e social, ou seja, a pessoa em seu relacionamento com a sociedade) (BITTAR, 1989, p. 17).

Portanto, ao satisfazer aspirações e necessidades próprias do indivíduo considerado em si mesmo, estão compreendidos, por isso, na esfera do interesse privado - constitui um direito subjetivo privado; ao relacionar seu objeto como um modo de ser físico ou moral da pessoa, bem se compreende como ele nunca contenha em si mesmo uma utilidade imediata de ordem econômica, incluindo-se entre os direitos nãopatrimoniais; ao confrontar, numa relação jurídica, com outros seres, compreendidos em sua generalidade, são absolutos (CUPIS, 2004, p. 34$37)$.

Constata-se, portanto, que os direitos da personalidade abrangem um complexo valorativo -- tese anteriormente exposta (Perlingiere) -intrínseco (intelectual e moral) e extrínseco (físico) do ente, alcançando a pessoa em si ou integrada à sociedade, possuindo como objeto seus atributos substanciais e, como fundamento, a própria essencialidade do ser.

No mais, percebe-se, pois, que o tratamento dispensado aos direitos da personalidade até a publicação do Código Civil de 2002 estava inserido na Constituição Federal/88, apesar desse direito ser uma matéria suficientemente específica para dar origem a um novo ramo. A Lei Maior de 1988 reclamou, pois, a adoção de dispositivos específicos à matéria ao legislador ordinário, a fim de adequar o direito à realidade.

E esta foi a regulamentação seguida pelo Novo Diploma Civil, estabelecendo um regime comum aplicável aos direitos da personalidade e à previsão de alguns direitos da personalidade em espécie, regulando 
aspectos sobre o corpo, o direito ao nome ou o direito à imagem, não suficientemente versados na Constituição Federal de 1988 (BELTRÃO, 2005, p. 45-46).

É dedicado, pois, um capítulo da parte geral aos direitos da personalidade (art. 11 e segs), selecionando aqueles que produzem efeitos mais agudos nas relações civis, a saber: direito à integridade física; vedação de tratamento médico ou intervenção cirúrgica não consentidos; direito à identidade pessoal; direito à imagem; direito à honra; direito à vida privada (LÔBO, 2001, p. 92). Essa previsão restrita a alguns direitos da personalidade ocorre porque a matéria é definida como complexa e de significação ética essencial, deixando-a para o natural desenvolvimento da doutrina e da jurisprudência.

Inicia-se, a exposição, com disposição genérica, quanto às suas características, definindo-os, salvo casos previstos em lei, como: intransmissíveis e irrenunciáveis, não podendo o seu exercício sofrer limitação voluntária (art. 11), salvo a que não seja permanente ou que afete seu núcleo essencial.

Versa sobre o direito de disposição do corpo, vedando os atos que importem em sua diminuição permanente (art. 13), sendo apenas essa situação admitida se impuser exigência médica. Assim, não se permite a mutilação do próprio corpo, salvo o que é renovável, como se dá com o corte dos cabelos e das unhas e a doação de sangue, ou de transplante de órgãos duplos ou de partes de órgãos, sem prejuízo das funções vitais, o que constitui o direito à integridade física (BITTAR, 1989, p. 40).

Enquanto o art. 13 estabelece a disposição (do corpo) em vida, o art. 14 dispõe sobre essa capacidade - de dispor - depois da morte, sendo válido, desde que tenha um fim científico, ou altruístico, podendo esse ato ser revogado a qualquer tempo. Portanto, a doação do corpo, ou de partes, para depois da morte deve atender os seguintes requisitos: a) deve ser feita a remoção depois da morte; b) o objetivo deve ser científico ou altruístico; c) deve haver autorização do doador ou de sua família (MONTEIRO, 2003, p. 98).

Portanto, o direito à integridade física tem por objeto a preservação da intocabilidade do corpo físico e mental da pessoa humana.

Prevê, ainda, que ninguém pode ser constrangido, com respeito ao direito à vida, a tratamento médico ou a intervenção cirúrgica, sendo, pois, essencial, o consentimento do paciente (art. 15), o que incidiria, também, na violação da integridade psíquica, cabendo uma indenização 
compensatória por danos morais, independentemente de prova, bastando estar ausente o consentimento É evidente que na medicina se busca a cura, não o fim da vida. O direito à vida é inerente a pessoa, mas também constitui um dever a mesma, que não pode dele dispor, por isso, é incompatível com o consentimento a ato contra a vida. A única limitação admitida constitucionalmente a este direito é relativa a pena de morte em caso de guerra declarada (art. $5^{\circ}$, XLVII, "a"). Aqui, pode-se incluir, ainda, o direito à saúde, embora nossa Constituição prefira qualificá-lo como direito social (art. 196), é o que se constata do trecho abaixo:

O caráter "social" que a Constituição empresta ao direito à saúde está a indicar que não é inerente à personalidade, até mesmo porque seu exercício pode estar condicionado a determinado preço. Apenas indiretamente a saúde interessa aos direitos da personalidade, na medida em que contribua para a afirmação do direito à vida, que não é direito social. (LÔBO, 2009, p. 147)

Outro direito assegurado é o direito geral à liberdade, o qual significa o direito de não estar subjugado a outrem, salvo a restrição em virtude do cometimento de crime. A prisão não extingue esse direito, apenas o limita em caso de cometimento de crime, tanto é que a Constituição não admite a prisão perpétua (art. $5^{\circ}$, XLVI, "a"), nem o desrespeito à integridade física e moral do presidiário (art. $5^{\circ}$, XLIX). Todavia, sua privação indevida dá ensejo à reparação compensatória por danos morais.

Outrossim, não se deve confundi-lo com liberdade econômica (art. $1^{\circ}, \mathrm{IV} \mathrm{c} / \mathrm{c}$ art. 170, CF/88) e contratual, nem com liberdade política, esta é direito fundamental, porém exterior à pessoa, e, portanto, não inato.

Assegura o direito à identidade pessoal, isto é, direito a ter nome, que é absoluto e inato (art. 16). O nome é composto de prenome e sobrenome. O primeiro, simples ou composto, é individual; enquanto o segundo indica a procedência familiar. É válido ressaltar que para a perspectiva que aqui interessa e sustentada por Pietro Perlingieri, deve-se evidenciar que todo nome é sempre expressão de um grupo familiar que tem a sua história e a sua reputação (1997, p. 180). Durante muito tempo, o prenome foi imutável, salvo hipóteses estreitas de erro gráfico ou ridicularização, permitindo sua alteração durante o primeiro ano após adquirir a maioridade. Essa regra foi mudada pela Lei 9708, de 1998, que admite a mudança por apelidos públicos notórios, ou seja, quando uma 
pessoa é conhecida no meio social por nome diverso do que foi registrada (LÔBO, 2001, p. 91).

No tocante ao direito ao segredo e à imagem (art. 20), ambos constituem o direito à privacidade e impedem a divulgação de escritos, a transmissão de palavras, ou a publicação e exposição ou a utilização da imagem da pessoa que afetem a honra, boa fama ou respeitabilidade, ou se se destinarem a fins comerciais, salvo se autorizadas ou se necessárias à administração de justiça ou à manutenção da ordem pública.

Interessante pontuar que sua "origem é da privacy norteamericana como direito de estar só, o que o tornaria 'um direito associal', que em si nada tem a ver com o desenvolvimento da pessoa, o que prejudica sua eficaz proteção legal" (LÔBO, 2009, p. 150); uma vez que deve ser analisada a pessoa em si mesma e em sua projeção na sociedade.

Outrossim, o direito à privacidade é gênero do qual são espécies o(a): intimidade (situações do domínio exclusivo da pessoa, o que torna seu conteúdo relativo de pessoa para pessoa, dependente da cultura, época e lugar), vida privada (situações concernentes ao ambiente familiar e cuja lesão resvala em outros membros do grupo), sigilo (proteção ao conteúdo das correspondências e das comunicações, consistindo na liberdade de não se emitir o pensamento ou o sentimento), imagem (toda forma de reprodução da figura humana, cuja exposição não autorizada é repelida; comporta a imagem externa da pessoa - efígie - art. $5^{\circ}, \mathrm{X}$, e imagematributo, art. $5^{\circ}, \mathrm{V}$, ambos da $\mathrm{CF} / 88$ ). Não se deve confundir este último com o direito a honra, pois para lesionar aquele basta o direito a retrato não estar autorizado; e para lesionar este é preciso que além do direito à efígie não estar autorizado, também seja capaz de danificar a reputação da pessoa efigiada. Há que se pontuar, então, que a violação da imagem pode ensejar, também, violação à honra. Portanto, a violação à honra atinge a reputação, respeito e boa fama que a pessoa desfruta nas relações sociais, é algo construído no ambiente social. Tem-se a subjetiva, a qual pertence à pessoa física, pois a mesma pode sofrer constrangimento ou vexames; e a objetiva, no caso das pessoas jurídicas, a qual depende de consideração, apreço e estimas sociais.

Uma questão discutida diz respeito à privacidade da pessoa com vida pública, pois há uma esfera mínima de proteção da sua privacidade a ser observada. Outrossim, não se inclui no âmbito do direito da personalidade o sigilo bancário, pois exprime um valor patrimonial do banco ou do cliente, embora o STF já tenha decidido que é uma espécie de 
direito à privacidade, só podendo ser violado por intervenção da autoridade judiciária.

Deve-se, ainda, mencionar os direitos morais do autor, como o direito à paternidade, à nominação ou ao ineditismo, etc. como conteúdo dos direitos da personalidade, previstos na Lei 9610/98.

Urge, ainda, salientar que o reconhecimento da existência desses direitos ficaria incompleto sem a necessária proteção da lei. Por esse motivo, dispõem os arts. 12 e 20 sobre a titularidade daqueles que podem exigir que cessem a ameaça, ou a lesão, a direito da personalidade, e reclamar perdas e danos, sem prejuízo de outras sanções previstas em lei (MONTEIRO, 2003, p. 97).

Impõe-se salientar que a pessoa jurídica, bem como entes não personalizados, mas que são equiparados à esta para determinadas finalidades legais, como condomínio edilício, espólio, massa falida, família etc., estão amparados por alguns direitos à personalidade, como: a honra objetiva e a privacidade ou imagem social, com retratação ou exposição indevidas de seus estabelecimentos e instalações; ou quando da violação de suas correspondências ou, ainda, do direito moral do autor de programas de computador, quando estes forem desenvolvidos por seus empregados, contratados para tal fim (Lei 9609/98) . O que é reforçado pela Súmula 227 do STJ.

É fácil constatar que o direito é reflexo da noção de pessoa humana, anterior, mesmo, a ordem jurídica. Esta constrói, assim, a noção de personalidade com base em dado ontológico (pessoa é), bem como em valores que lhe são imanentes (axiológico). Consubstanciando no fenômeno da repersonalização do direito, desloca-se a preocupação do legislador com a pessoa, anteriormente centrada no ter e, hoje, no ser. Por isso, nos direitos da personalidade o aludido fenômeno atinge seu ponto máximo, como conjunto de atributos inerentes à condição humana.

No mais,

o intérprete deve estar atento para a diversidade de princípios e de valores que inspiram a pessoa física e a pessoa jurídica, e para que esta, como comunidade intermediária constitucionalmente privilegiada, seja merecedora de tutela jurídica e tão-somente como um instrumento (privilegiado) para a realização das pessoas que, em seu âmbito de ação, é capaz de congregar (TEPEDINO, 1999, p. 53). 


\section{$1.3 \quad$ ATRIBUTOS}

Constata-se que a existência peculiar dos direitos da personalidade, torna-os proeminentes relativamente a todos os outros direitos da pessoa a que respeitem. A natureza não patrimonial e a circunstância de serem inatos e essenciais à realização da pessoa, exigências que lhes são peculiares, refletem características que os singularizam (LÔBO, 2001, p. 82).

Outrossim, é oportuno ressaltar que, por serem não patrimoniais, "encontram excelente campo de aplicação nos danos morais, que igualmente não são patrimoniais" (LÔBO, 2001, p. 138), e, ainda, ambos (direitos da personalidade e direitos morais) têm "por objeto bens jurídicos integrantes da interioridade da pessoa" (LÔBO, 2001, p. 138). Assim sendo, observa-se que "os danos morais constituem a sanção adequada ao descumprimento do dever absoluto de abstenção de violação dos direitos da personalidade" (LÔBO, 2001, p. 138), conforme se depreende de sua inserção constitucional (art. $5^{\circ}, \mathrm{X}, \mathrm{CF} / 88$ ), ou seja, havendo violação do direito da personalidade, surge o direito à reparação pelo dano moral, independentemente da comprovação da dor ou prejuízo, basta o nexo de causalidade, cabendo ao juiz fixar o quantum da indenização compensatória, a qual não pode ser simbólica nem demasiada, utilizandose do princípio da proporcionalidade.

De fato, é importante salientar, como demonstra Silvio Beltrão (2005, p. 27), que o Código Civil de 2002 (art. 11) preceitua algumas dessas características ao destacar os aspectos intransmissível e irrenunciável do tema, configurando-os como resultado da infungibilidade própria da pessoa, diante do nexo entre o direito e a personalidade. Podese acrescentar que são também absolutos, vitalícios e incondicionais.

Insta, pois, destacar seus elementos substanciais, os quais estão intrinsecamente relacionados, ou seja, o conteúdo de um reflete necessariamente na dimensão do outro. São eles: intransmissibilidade, indisponibilidade, irrenunciabilidade, imprescritibilidade.

Preliminarmente, nos direitos da personalidade, a intransmissibilidade repousa no âmago do objeto, cuja identidade corresponde aos bens mais elevados da pessoa, situados em um liame de natureza orgânica. A importância desse caráter consubstancia a própria essência da matéria, pois nem mesmo o ordenamento jurídico pode consentir que o ser humano se despoje dos aludidos direitos, justamente 
por representarem os bens máximos da pessoa, não podendo, pois, serem objeto de cessão e até mesmo de sucessão, seja por ato gratuito ou oneroso (PEREIRA, 2004, p. 242). Ou seja, por não serem objetos externos à pessoa, não podem ser disponíveis, nem pode ser de domínio público ou coletivo, bem como não pode ser objeto de execução ou penhora judicial, em outras palavras, são inexpropriáveis. Dependendo, portanto, seu exercício apenas da vontade do indivíduo.

Todavia, há certos aspectos que podem ser objeto de transmissão, demonstrando, inicialmente, uma aparente contradição, é o que se constata da passagem do trecho abaixo:

O direito de imagem-retrato é transmissível, por exemplo, principalmente nos casos de pessoas que vivem profissionalmente da exposição pública, como os modelos, os artistas, os desportistas. A Lei de Direitos Autorais admite expressamente o chamado direito de arena, para pessoas que não são criadores ou autores, mas cujas habilidades corporais, físicas ou dramáticas os singularizam, atraindo público e gerando renda para si e para as organizações que as utilizam; são situações essencialmente patrimoniais e, portanto, transmissíveis, não podendo terceiro fazer uso delas para proveito próprio sem autorização. Porém, um esclarecimento se impõe, para se ultrapassar a contradição, é dizer, o que se transmite não é o direito da personalidade, mas a projeção de seus efeitos patrimoniais, quando haja...A regra do Código Civil está, portanto, correta (LÔBO, 2009, p. 141).

Portanto, quer sejam esses direitos inatos ou adquiridos, são eles intransmissíveis. Toda transmissão supõe que uma pessoa se ponha no lugar de outra; se a transmissão se pudesse dar, o direito não seria de personalidade. Não há, portanto, qualquer sub-rogação pessoal; nem poderes contidos em cada direito de personalidade, ou seu exercício, são suscetíveis de ser transmitidos ou por outra maneira outorgados (MIRANDA, 2000, p. 31-32).

Percebe-se que a intransmissibilidade pode parcialmente reconduzir à indisponibilidade, ou falta, no sujeito, da faculdade ou poder de disposição, como assevera De Cupis (2004, p. 56), eis que

A relação existente entre a transmissibilidade e a disponibilidade compreende-se com facilidade, desde que uma das causas de mudança do sujeito dos direitos é precisamente a vontade do seu titular, a qual reveste relevância jurídica por virtude da existência da referida faculdade de disposição. 
Assim, os direitos da personalidade, enquanto intransmissíveis, são também indisponíveis, não sendo permitida a mudança de sujeito, nem pela vontade do próprio titular. São, pois, subtraídos de disposição individual, tanto como a própria personalidade. É oportuno mencionar que nem mesmo a temporária disponibilidade, a qual é permitida, retira a atribuição de vitaliciedade. É o que se depreende da passagem a seguir transcrita, sustentada por Gilberto Jabur (2000, p. 45, 55), in verbis:

A temporária disponibilidade, que hoje em dia é freqüentemente responsável pela reversão de frutos econômicos ao titular da declaração de vontade, não desmerece a atribuição da vitaliciedade. Porque, sendo irrenunciáveis, não autorizam a alienação, tampouco a transmissibilidade absoluta de seu conteúdo. Há, isto sim, parcial e temporária limitação de exercício, mediante excepcional e restrito consentimento do titular. [...] É que, se os direitos da personalidade não podem, por um lado ser destacados da pessoa, porque "fazem corpo com ela", como enfatizam os Mazeud, a fruição e a exploração de algumas de suas faculdades encontra licitude, por não ofenderem a preservação do direito de que emanam. É o caso da utilização e publicação consentida do retrato, da divulgação autorizada de aspectos íntimos e da tolerância da ofensa à honra. $\mathrm{O}$ direito permanece intacto. Suas potencialidades são cedidas temporariamente, no que consiste a faculdade máxima de disposição humana.

Ademais, como resultado do caráter indisponível, são inexpropriáveis porque estão fora do domínio público ou coletivo, de modo que o Poder Público não pode pretendê-los. Significa dizer que os direitos da personalidade não são suscetíveis de execução forçada, ou seja, não pode haver transferência do direito de um sujeito para outro, sem o pressuposto da vontade (disposição): o Estado, mediante um ato de império, de um lado não pode privar do direito o titular originário, e de outro o atribuir ao adquirente. À execução estão somente submetidos os direitos patrimoniais transmissíveis (CUPIS, 2004, p, 65). A relevância do assunto pode ser percebida no texto abaixo colacionado:

\footnotetext{
Possibilitar, em sede de direitos personalíssimos, a execução forçada e a consequente penhora, fases do processo de expropriação, é o mesmo que desprover a própria personalidade das projeções e faculdades mínimas para seu desempenho sadio e harmônico. É privá-la do desenvolvimento ideal que sua natureza reclama (JABUR, 2000, p. 62).
}

Por sua vez, a irrenunciabilidade enuncia que o indivíduo não pode abdicar de seus direitos da personalidade. Válido destacar que o não 
exercício dos mesmos por longo tempo, não configura o fenômeno da renúncia, pois, que, aqueles são indissociáveis da pessoa. Observa-se que a faculdade de renúncia está inserida na faculdade de disposição, esta compreendida em seu sentindo amplo, por isso, afirmar que um direito é indisponível é dizer que o mesmo é irrenunciável.

Dessa forma, aduz Pontes de Miranda (2000, p. 32) que "A razão para a irrenunciabilidade é a mesma da intransmissibilidade: ter ligação íntima com a personalidade e ser eficácia irradiada por essa. Se o direito é direito de personalidade, irrenunciável é”.

Outrossim, é permitido restringir o desempenho desses direitos em alguns casos, por meio de negócios jurídicos, sem que haja a extinção dos mesmos, uma vez que podem ser reestabelecidos a qualquer momento. Situação essa defendida por Carlos Bittar (1989, p. 12) ao estabelecer que

\footnotetext{
Mas, frente a necessidades decorrentes de sua própria condição, da posição do titular, do interesse negocial e da expansão tecnológica, certos direitos da personalidade acabaram ingressando na circulação jurídica, admitindo-se ora a sua disponibilidade, exatamente para permitir a melhor fruição por parte de seu titular, sem, no entanto, afeta-se os seus caracteres intrínsecos.
}

O importante é mencionar que esses limites negociais estão subordinados às convenções estabelecidas pelas partes e às disposições legais. A disponibilidade dos direitos é uma qualidade que não pode jamais se verificar relativamente a um só e determinado setor do ordenamento jurídico, compreende o caráter geral da ordem pública e dos bons costumes (CUPIS, 2004, p. 63). Assim, são disponíveis, contratualmente (licença, cessão de direitos e outros instrumentos específicos), certos direitos, os quais poderão ser utilizados por terceiro, porém adstrito aos ajustes negociais.

A fim de reforçar a sujeição desse negócio jurídico às normas legais, o Código Civil de 2002 esclarece que a limitação voluntária do exercício dos direitos da personalidade somente poderá ocorrer nos casos previstos em lei, o que torna a exegese de difícil compreensão, pois é bastante complicado normatizar quais atos podem sofrer ou não a referida limitação voluntária. Cabe, pois, ao hermeneuta, em cada caso, analisar se essa restrição viola o princípio geral da preservação da dignidade humana e o respeito ético da pessoa humana como atributo de uma cláusula geral (BELTRÃO, 2005, p. 29-30). 
Dessa forma, o consentimento do titular de direito não fere o princípio inerente à dignidade da pessoa humana, o qual poderá ser revogado, cabendo, porém, ao titular do direito indenizar o dano causado às legítimas expectativas da outra parte.

Enfim, os direitos da personalidade devem necessariamente permanecer na esfera do próprio titular, gozando do elemento tempo e tornando-os imprescritíveis, devido à faculdade contínua de seu exercício. Assim, não podem ser adquiridos por outrem, nem são sujeitos à execução forçada. As pretensões e ações, que se irradiam deles, não prescrevem. Nem precluem as exceções. A imprescritibilidade decorre do fato de que a pretensão ou a exigência de seu cumprimento não se sujeita a liames temporais, podendo a qualquer tempo ser exercidos.

Outrossim, dúvidas existem relativamente à prescrição, pois de acordo com o art. 206, CC/02, a pretensão para reparação civil prescreve em 3 anos. Dessa forma, se a violação dos direitos da personalidade enseja reparação compensatória em razão do dano moral, esta deve ser pleiteada dentro do prazo legal. Situação essa que poderia gerar uma certa contradição, já que os direitos da personalidade são imprescritíveis, extinguindo-se com a pessoa. Assim, a fim de esclarecer o impasse, segue o ensinamento do aludido doutrinador, in verbis:

\footnotetext{
Todavia, não se prescrevem as demais pretensões decorrentes da violação dos direitos da personalidade, que não têm natureza pecuniária. São imprescritíveis as pretensões relativas a fazer cessar a violação ou para a interdição de preventiva, apesar de ultrapassados os três anos, ou para obrigações de fazer. Os direitos da personalidade, por si mesmos, são inatingíveis pela prescrição (LÔBO, 2009, p. 142).
}

É sabido que a concepção atual de responsabilidade civil exige, em razão da constitucionalização do direito civil, a primazia do interesse da vítima, a reparação completa e a solidariedade social. Desta feita, a reparação não se reduz ao aspecto pecuniário, mas deve ser completa, ensejando, ainda, uma obrigação de fazer ou de se abster, ou até direito a resposta, não cabendo, aqui, falar em prescrição.

É oportuno esclarecer que não se deve vincular o seu caráter absoluto com a ideia de erga omnes ou oponibilidade a terceiros, mas sim como sinônimo de preponderância quando analisados frente a outro direito. É o que se depreende do entendimento de Gilberto Jabur (2000, p. 70), eis que 
O vocábulo absoluto traz imediata ideia de preponderância, predomínio, supremacia. Convém, por isso, não tê-lo como sinônimo de erga omnes. Porque se são direitos que a todos se opõem, infundindo o dever geral de abstenção, não quer isto significar que sejam ilimitados, mesmo que se pretenda dizer que são absolutos ou irrestritos até colidirem com direitos de igual categoria ou graduação (personalíssimos), quando então se processaria natural acomodação dos valores da personalidade.

Convém, ainda, destacar que a chamada sub-rogação, ou seja, a transferência de titularidade desses direitos e das faculdades de gozo, fere os caracteres da intransmissibilidade, indisponibilidade, irrenunciabilidade e imprescritibilidade, sendo, portanto, proibida a sua aplicação aos direitos da personalidade.

Válido ressaltar que mesmo após a morte da pessoa, não pode haver violação dos direitos da personalidade, pois, caso contrário, seus familiares estariam legitimados a pleitear a ameaça ou cessação dos mesmos. Lembrando que quem está legitimado à defesa não exerce direito próprio, mas direito de outrem, em razão dos aspectos patrimoniais decorrentes da reparação civil. Podendo, todavia, os familiares serem atingidos diretamente, nas hipóteses em que a ofensa não apenas lesa os direitos do falecido, mas se estende a seus familiares, exercitando direito próprio.

Do exposto, torna-se fácil constatar o relacionamento intrínseco entre essas características, ou mesmo princípios, que norteiam os direitos da personalidade. Figura a intransmissibilidade como o princípio máximo ou gênero, do qual as demais qualidades são frutos ou espécie. Funcionam, pois, como instrumentos realizadores da dignidade da pessoa humana.

Portanto, esses atributos integram o conteúdo e âmbito dos direitos da personalidade, local onde o fenômeno da repersonalização do direito civil atinge seu ápice: a pessoa na sua ontologia!

\section{DA INSERÇÃO DA DIGNIDADE DA PESSOA HUMANA SOBRE OS DIREITOS DA PERSONALIDADE}

Do exposto, pode-se afirmar, portanto, que esse conjunto de direitos decorre não apenas da previsão constitucional e das leis especiais, mas das infinitas manifestações do desenvolvimento humano, o que consubstancia o princípio da dignidade da pessoa humana. 
Dessa forma, os direitos da personalidade assumiram seu papel fundamental de realização da pessoa humana na Lei Maior de 1988, a qual consagrou, modernamente, diversos direitos e garantias fundamentais, como a integridade física, a liberdade de manifestação religiosa, artística, intelectual e científica, a intimidade, a honra, a imagem, constitucionalizando, enfim, a dignidade da pessoa humana como um dos valores relevantes inerentes à pessoa.

A constitucionalização dos institutos do direito privado e a consequente análise da pessoa em toda sua ontologia foram fatores determinantes que estimularam a modificação do Diploma Civil, tornandoo mais coerente com a realidade e com os ideais do Estado social, consagrados na Carta Magna de 1988.

Compreender o espírito da Constituição Federal de 1988 é compreender a passagem do Estado liberal para o social e, consequentemente, a superação da tradição patrimonialista pela tendência a uma repersonalização. Configurando-se, a partir daí, a inserção das normas constitucionais sobre os institutos codificados, o que enseja o processo de constitucionalização do direito civil.

Então, não há mais dúvida de que o Direito Civil deve ser interpretado segundo a Lei Maior, jamais o contrário. O direito civil constitucional tem a tarefa de harmonizar o direito civil aos princípios constitucionais ou à Constituição como um todo orgânico. Daí, o sentido técnico, talvez o mais correto, emprestado à constitucionalização do direito civil, seria aquele no qual a Lei Maior, sem sufocar a vida privada e suas relações, dá maior força ou credibilidade aos institutos codificados, revitalizando-os, mediante nova tábua axiológica. E este é o novo papel assumido pela Constituição: o papel de vértice axiológico do sistema.

Insta, pois, repisar a lição de Paulo Lobo (1999, p. 100) sobre o tema, a fim de sintetizar o exposto anteriormente, pois que "... a constitucionalização é o processo de elevação ao plano constitucional dos princípios fundamentais do direito civil, que passam a condicionar a observância pelos cidadãos, e a aplicação pelos tribunais, da legislação infraconstitucional."

De fato, a constitucionalização dos institutos do direito privado faz com que se repense o direito no contexto de uma ordem capaz de vincular lei e realidade. Este modelo epistemológico significa que os resultados apontados jamais poderão ser únicos, devendo ser adequados para a situação, momento e local específicos a que se dirigem, sob pena de 
criar-se uma nova ficção, divorciada da realidade e sem condição de atender, com sucesso, aos reclamos daquela determinada tensão ou emergência social.

É o que ocorre com os direitos da personalidade. Com o advento da Carta Magna de 1988, tornou-se imprescindível a disciplina da matéria pelo Novo Código Civil. Refere-se o texto constitucional, ao lado das liberdades e do sigilo, especialmente a: intimidade; vida privada; honra; imagem das pessoas (art. $\left.5^{\circ}, \mathrm{X}\right)$. A proteção constitucional tem por objetivo assegurar a cada qual a respectiva integridade, evitando-se que esses bens sejam oferecidos a conhecimento, ou a fruição de terceiros, ou mesmo submetidos a ações deletérias ou depreciativas, enfim, a resultados não desejados pela pessoa e, portanto, contrários à ordem jurídica, como bem observa Carlos Bittar (1989, p. 60).

A Constituição Federal brasileira cuida, em outras passagens, dos direitos da personalidade, havendo quando da sua violação relação com danos morais, explícita ou implicitamente. É o que se depreende da leitura do art. $5^{\circ}$, caput, incisos V, X, XI, XII, XLVII, LIV, LXXV; art. 199, §4; art. $225, \S 1^{\circ}, \mathrm{V}$; art. 227 , caput, $\S 6^{\circ}$; art. 230 . Válido ressalvar que a realização desses direitos, especificamente o sigilo e a honra, ocorre por meio do habeas data (art. $5^{\circ}$, LXXIII), regulamentado pela Lei ${ }^{\circ} 9505$, de 1997 (LÔBO, 2001, p. 92-94).

É importante mencionar a constante remissão dessas normas à dignidade humana, a demonstrar a sua natureza de princípio fundamental ou de cláusula geral e, também, de parâmetro para as situações subjetivas atípicas de direitos da personalidade.

Na verdade, esses direitos constituem criação pretoriana, pois são nos tribunais que eles vêm adquirindo forma, força e consistência. A jurisprudência tem procurado deduzir os princípios e características comuns dos diferentes direitos, no sentido de assentá-los, possibilitando a sua sistematização. Isso ocorre porque as incursões na vida privada, especialmente ditadas pela evolução da tecnologia e das comunicações, têm exigido o reconhecimento expresso desses direitos e a sua regulamentação, para garantir-lhes proteção no âmbito privado.

Pode-se dizer, então, que o direito da personalidade é fruto das evoluções industriais e de massa, e, em especial, do desenvolvimento tecnológico, o qual permite a identificação de novas relações do homem com o mundo, com seu próprio semelhante, e consigo mesmo, 
proporcionando uma valorização do indivíduo. Vislumbra-se, mais uma vez, o fenômeno da repersonalização.

Dessa forma, a restauração da primazia da pessoa humana representa, portanto, a condição primeira de adequação do direito à realidade e aos fundamentos constitucionais (LÔBO, 1999, p. 103).

Com efeito, válido ressaltar o entendimento de Gilberto Haddad Jabur (2000, p. 38) sobre a intercessão entre os temas direitos da personalidade e repersonalização, pois, que

Os direitos da personalidade assim efetivamente se afirmaram por obra da elaboração prática e teórica do presente século, como consequência das evoluções industriais (Antonino Scalisi fala em "Revolução industrial") e de massa, e do incessante desenvolvimento tecnológico responsável pela identificação de novas relações do homem com o mundo, com seu próprio semelhante, e consigo mesmo, propondo, por tais razões, uma valorização do indivíduo, pelo que ele representa na realidade da vida.

\section{REFERÊNCIAS BIBLIOGRÁFICAS}

BELTRÃO, Silvio Romero. Direitos da personalidade: de acordo com o Novo Código Civil. São Paulo: Atlas, 2005

BITTAR, Carlos Alberto. Os Direitos da Personalidade. Rio de Janeiro: Forense Universitária. 1989

CUPIS, Adriano de. Os direitos da personalidade. Tradutor: Afonso Celso Furtado Rezende.

Campinas: Romana, 2004

D’OLIVO, Maurício. O Direito à Intimidade na Constituição Federal de 1988. Cadernos de Direito Constitucional e Ciência Política. São Paulo: Revista dos Tribunais, ano 4, n. 15, Abril/Junho de 1996

DINIZ, Maria Helena. Curso de Direito Civil Brasileiro. São Paulo: Saraiva, vol. 1º 1994, p. 83 e 84

DINIZ, Rivanildo Pereira. A proteção constitucional da vida privada e a reparação do dano moral. Cadernos de Direito Constitucional e Ciência Política. São Paulo: Revista dos Tribunais, ano 7, n. 29, outubro-dezembro, 1999

FACHIN, Luiz Edson (coordenação): Carmem Lucia Silveira Ramos e outros. Repensando fundamentos do direito civil contemporâneo. Rio de Janeiro: Renovar, 1998

FREGADOLLI, Luciana. O direito à intimidade. Cadernos de Direito Constitucional e Ciência Política, São Paulo: Revista dos Tribunais, ano 5, n. 19, abril-junho de 1997 
GOMES, Orlando. Introdução ao Direito Civil. Rio de Janeiro: Forense, 1974

JABUR, Gilberto Haddad. Liberdade de pensamento e direito à vida privada: conflitos entre direitos da personalidade. São Paulo: Editora Revista dos Tribunais, 2000

LÔBO, Paulo Luiz Netto. Constitucionalização do Direito Civil. Revista de Informação Legislativa. Brasília: Senado Federal, nº 141, jan./março 1999

LÔBO, Paulo Luiz Netto. Danos morais e direitos da personalidade. Revista trimestral de direito civil. Rio de Janeiro: Patmas, $\mathrm{n}^{\circ}$ 6, abr/jun 2001

LÔBO, Paulo Luiz Netto. Teoria geral das obrigações. São Paulo: Saraiva, 2005

LOBO, Paulo. Direito civil: parte geral. São Paulo: Saraiva, 2009

LORENZETTI, Ricardo Luis. A descodificação e a possibilidade de ressistematização do direito civil. In FIÚZA, Cesar et al (Coords). Direito Civil: Atualidades. Belo Horizonte: Dey Rey, 2003

MIRANDA, Pontes de. Tratado de direito privado. Campinas: Bookseller, vol. 7, 2000

MIRANDA, Pontes. Tratado de Direito Privado. V. VII, Rio de Janeiro: Borsoi, 1971

MONTEIRO, Washington de Barros. Curso de direito civil. São Paulo: Saraiva, vol. 1, 2003

PEREIRA, Caio Mário da Silva. Instituições de direito civil. Rio de Janeiro: Forense, vol. 1, 2004

PERLINGIERI, Pietro. O direito civil na legalidade constitucional. Rio de Janeiro: Renovar, 2008, pp. $177,577,579,584 / 585,589,591$

PERLINGIERI, Pietro. Perfis do Direito Civil - Introdução ao Direito Civil Constitucional. Trad: Maira Cristina de Cicco, Rio de Janeiro: Renovar, 1997

TEPEDINO, Gustavo. Normas constitucionais e relações de direito civil na experiência brasileira. Boletim da Faculdade de Direito Stulia Juridica, $n^{\circ} 48$, Colloquio 6. Universidade de Coimbra: Coimbra Editora, 2000

TEPEDINO, Gustavo. Temas de direito civil. Rio de Janeiro: Renovar, 1999 